\title{
Evaluation of Dynamic Modulus of Asphalt Concrete Field Cores
}

\author{
[ Md Ohiduzzaman, Okan Sirin, Emad Kassem ]
}

\begin{abstract}
The dynamic modulus is a required parameter in the design and analysis of asphalt pavements. The dynamic modulus of asphalt mixtures increases with aging as the mixture becomes stiffer. This paper presents an experimental evaluation of dynamic modulus of asphalt concrete field cores in the State of Qatar where asphalt mixture is subjected to harsh weather condition of elevated temperature. A total number of six different pavement sections were selected to study the aging effect and mix design on the mechanical performance of asphalt pavements in Qatar. These six different sections were constructed by using different types of aggregates and different bitumen types. Field cores were extracted from these sites. The extracted field cores were sliced into base and wearing layers and dynamic modulus tests were performed on these specimens. The test results demonstrated that the effect of aging was more prominent in the wearing course of pavements as it is subjected to elevated temperatures compared to the base layer. Comparison of dynamic modulus master curves showed that the dynamic modulus of wearing asphalt mixture is higher in comparison to base mixture especially at high temperature-low frequency region. In addition, the results showed that asphalt mixtures prepared with modified binders showed higher dynamic modulus at high temperature-low frequency test condition in comparison to unmodified binders.
\end{abstract}

Keywords—dynamic modulus, stiffness, master curve, asphalt pavement, Qatar.

\section{Introduction}

Dynamic modulus is one of the important performance criteria to characterize the mechanical properties of asphalt mixtures. In the Mechanistic Empirical Pavement Design Guide (MEPDG), the dynamic modulus of asphalt mixture is a required input (NCHRP 2004). Previous studies demonstrated that dynamic modulus represents the stiffness of asphalt mixture subjected to a haversine load on a cylindrical specimen over a range of temperature and loading frequencies (NCHRP 2004).

Md Ohiduzzaman

Qatar University

Qatar

Okan Sirin

Qatar University

Qatar

Emad Kassem

University of Idaho

USA
Dynamic modulus is an important critical input parameter for its significant correlation with major pavement distresses such as rutting and fatigue cracking (Goh et al. 2011; Shenoy and Romero 2002; Witczak et al. 2002), therefore it is used to predict the performance of asphalt pavements (Yan-Zhu and Duan-Yi 2012). In addition, the characterization of asphalt mixture in MEPDG is only evaluated by using dynamic modulus along with asphalt binder and volumetric properties of asphalt mixtures.

Dynamic modulus test is a non-destructive test and generally performed by using an asphalt mixture performance tester (AMPT) equipment. The AMPT is a servo-controlled machine capable of producing a controlled, sinusoidal compressive loading on a cylindrical specimen. Generally, specimen is cored from the base layer of pavement and performance testing is conducted to analyze the mechanical properties of field asphalt mixture. However, the value of dynamic modulus can be different for wearing and base mixture as wearing mixture is directly exposed to environmental condition especially in the Gulf region where it is subjected to harsh environmental conditions. A recent study by Sirin et al. (2017) showed that asphalt binder in the wearing course in Qatar is more aged compare to base binder.

The standard size of asphalt mixture cylindrical specimen for the AMPT testing is $100-\mathrm{mm}$ in diameter and $150-\mathrm{mm}$ height. However, thickness of asphalt surface/wearing layer or any intermediate layer is generally less than $100-\mathrm{mm}$. Therefore, researchers sometimes tested small specimens which are cored from the wearing layer (Diefender et al. 2015). Dynamic modulus test results showed that small specimen (50-mm diameter and $110-\mathrm{mm}$ height) is viable alternative option for big size specimens of nominal maximum aggregate size of 25-mm (Diefender et al. 2015). The main objective of this study was to evaluate the dynamic modulus of cores extracted from in-service asphalt pavements in Qatar.

\section{Description of Field Test Sections}

Field cores were collected from 6 test sections which are located in zone 83 south of interchange 42 on the Salwa road in the State of Qatar. These test sections were constructed in 2010 to investigate the influence of materials (aggregates and asphalt binders) and mixture design on performance of flexible pavements. Each test section is about $150 \mathrm{~m}$ length. Table 1 shows the mixture design and materials used in each section. As can be seen in the Table 1, the wearing course for all test sections was constructed using gabbro aggregates imported from United Arab Emirates. The difference among the surface course layers is in the mixture design and bitumen type. Two different types of aggregate (gabbro and limestone) were used 
for the construction of asphalt base layer. The base layer also differed in bitumen type and mixture design. A same granular sub-base with limestone aggregate was used for all sections. Asphalt mix design is based on two specifications; Qatar Construction Specifications (QCS) which is essentially the Marshall Design method and Percentage Refusal Density (PRD) design method (BS EN 12697/32:2003, TRL 2002).

TABLE 1. MATERIALS AND MIX DESIGN USED FOR EACH TEST SECTION (TRL 2010)

\begin{tabular}{|c|c|c|c|c|c|c|}
\hline \multirow{2}{*}{ Sections } & \multicolumn{3}{|c|}{ Wearing Layer } & \multicolumn{3}{c|}{ Base Layer } \\
\cline { 2 - 7 } & $\begin{array}{c}\text { Mix } \\
\text { Design } \\
\text { Method }\end{array}$ & $\begin{array}{c}\text { Binder } \\
\text { Type }\end{array}$ & Aggregates & $\begin{array}{c}\text { Mix } \\
\text { Design } \\
\text { Method }\end{array}$ & $\begin{array}{c}\text { Binder } \\
\text { Type }\end{array}$ & Aggregates \\
\hline 1 & PRD & Pen $40-50$ & Gabbro & PRD & Pen 40-50 & Gabbro \\
\hline 2 & PRD & Pen 60-70 & Gabbro & PRD & Pen 60-70 & Gabbro \\
\hline 3 & PRD & Pen 60-70 & Gabbro & PRD & Pen 60-70 & Limestone \\
\hline 4 & QCS & Pen 60-70 & Gabbro & QCS & Pen 60-70 & Gabbro \\
\hline 5 & PRD & PMB & Gabbro & QCS & $\begin{array}{c}\text { Shell } \\
\text { Thiopave }\end{array}$ & Gabbro \\
\hline 6 & PRD & PMB & Gabbro & PRD & PMB & Gabbro \\
\hline
\end{tabular}

\section{Extraction of Cores from the Field}

Three cores (150-mm diameter and 330-mm height) from each pavement section were extracted in the field. These cores were collected from the wheel path of pavement. The field cores were extracted using a portable coring machine as shown in Fig. 1. This is a simple but rugged machine, which can be easily carried in a pick-up truck. The relatively heavy weight $(\approx 100 \mathrm{~kg}$ ) contributed stability to the machine during coring. Fig. 2 shows the dimensions of an extracted field core.

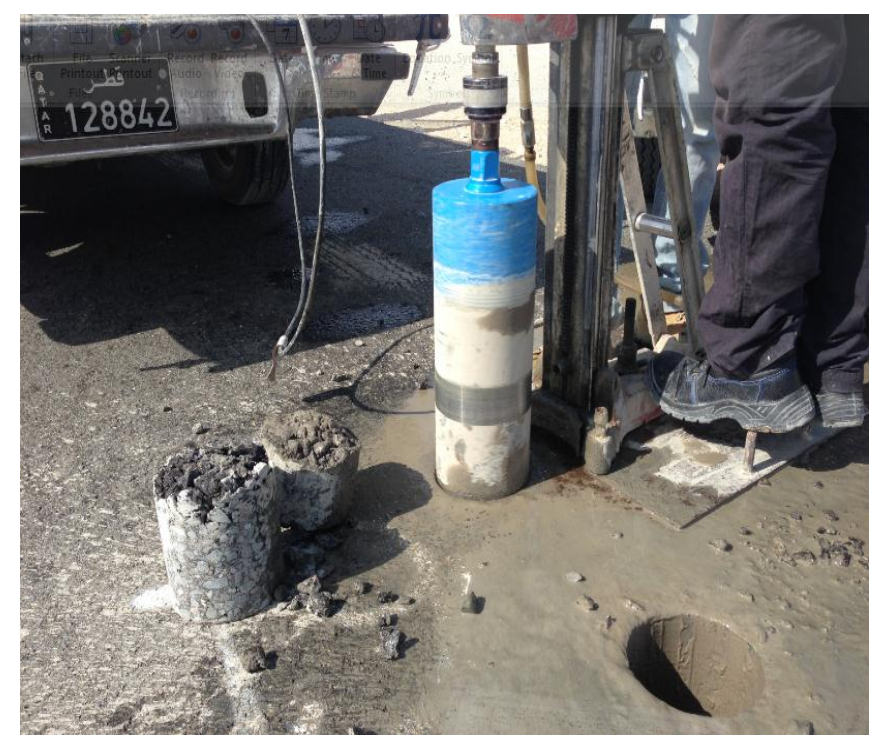

Figure 1. Extraction of field cores from the test sections

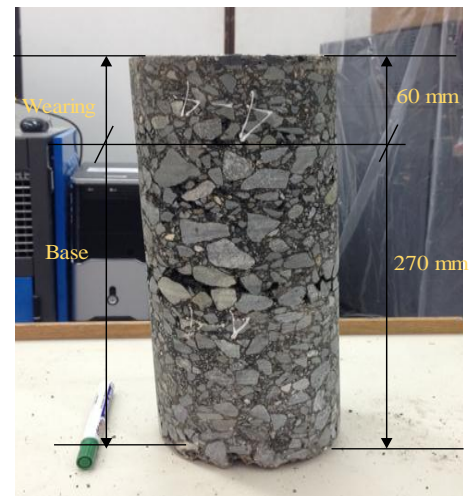

Figure 2. A typical field core extracted from the test sections

\section{Sample Preparation for Performance Testing in the Laboratory}

Each field core consisted of two layers: wearing and base layer. Aggregates gradation is different for base and wearing layers. Test specimens were prepared from both layers and performance testing was conducted using the AMPT to study the effect of aging on the mechanical properties of both layers. The base layer was cored and trimmed to $100-\mathrm{mm}$ diameter and $150-\mathrm{mm}$ height which was used in the testing. However, small specimens $(50-\mathrm{mm}$ diameter and $110-\mathrm{mm}$ height) were cored horizontally from the wearing course. The researchers used modified gluing jig of the AMPT equipment to accommodate the small test specimens as shown in Fig. 3. In addition, removable spacer block manufactured of aluminum was used to adjust the height of small scale specimen to fit in the AMPT machine. The bottom and top platens were also fabricated to match diameter of small scale specimen. These customs platens were manufactured from aluminum similar to the original AMPT platen. Top platen was also machined to facilitate centering of small scale specimen. Gauge length of the specimen was same $(70-\mathrm{mm})$ as that of standard AMPT specimen. The modified platen arrangement for wearing core is shown in Fig. 4.

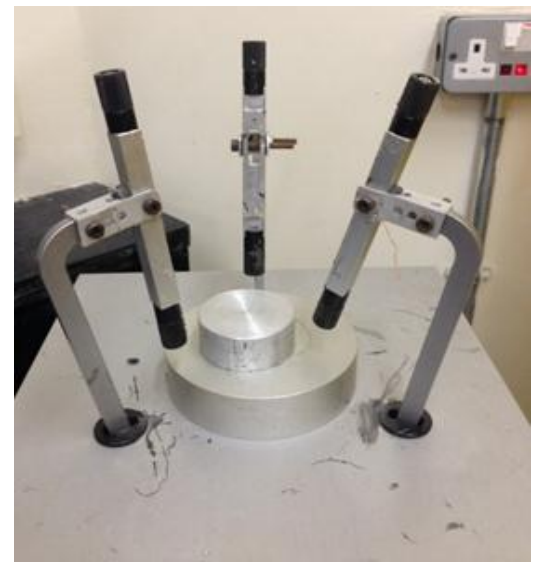

Figure 3. Modified gluing jig 


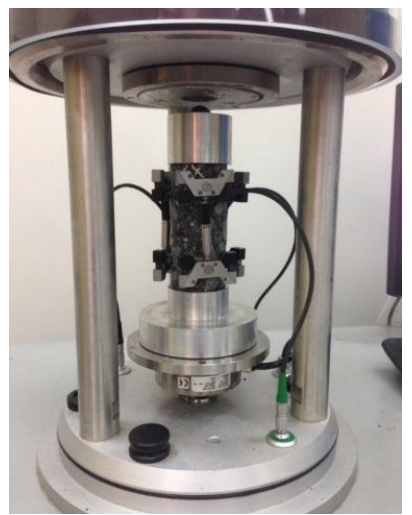

Figure 4. Modified platen arrangement for wearing core testing

\section{v. Testing of AMPT Specimens}

The specimens were tested to determine dynamic modulus $\left(\left|E^{*}\right|\right)$ and phase angle $(\delta)$ at different temperatures and over a range of frequencies. The test was conducted in an AMPT testing system made by IPC Global, Australia as shown in Fig. 5 . This machine consists of a confining pressure system and an environmental chamber, capable of controlling temperatures from 4 to $70^{\circ} \mathrm{C}$. Each specimen was tested at three different temperatures $\left(4^{0} \mathrm{C}, 20^{\circ} \mathrm{C}\right.$ and $\left.40^{\circ} \mathrm{C}\right)$. For $4^{\circ} \mathrm{C}$ and $20^{\circ} \mathrm{C}$, each specimen was subjected to three loading frequencies $(10,1.0$, and $0.1 \mathrm{~Hz})$ whereas four loading frequencies $(10,1,0.1$ and $0.01 \mathrm{~Hz}$ ) were applied at $40^{\circ} \mathrm{C}$. The dynamic modulus testing was started from the lowest to highest temperature and from highest to lowest frequency.

In the dynamic modulus test, a sinusoidal axial compressive load was applied without confining pressure under strain-controlled conditions. The strain amplitude was kept low enough [i.e. $60-90$ microstrain $(\mu \varepsilon)$ ] to ensure that the material does not go through plastic deformation. Also, the total permanent axial strain was limited to $1,500 \mu \varepsilon$ after all the testing to reassure the material reacted solely in a linear viscoelastic region. Three axial linear variable differential transformers (LVDTs) were used to measure the axial deformation during the test. The applied stress and recorded strain were used to calculate the dynamic modulus and phase angle. In general, the test was conducted in accordance with the AASHTO TP 62-1 (AASHTO 2007) standard procedure.

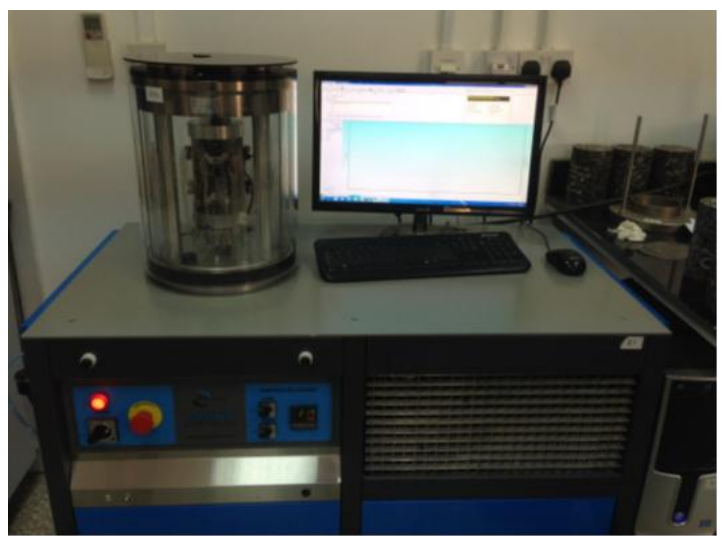

Figure 5. AMPT system for dynamic modulus test
A master curve based on the dynamic modulus values of asphalt mixture specimen at different temperature and loading condition is often constructed at an arbitrarily selected reference temperature (say $20^{\circ} \mathrm{C}$ ) to account for the influence of temperature and rate of loading. A master curve describes the viscoelastic property of asphalt mixture specimen at the reference temperature and over a range of time/frequency. The modulus master curve for asphalt mixtures can be represented by a sigmoidal function defined by equation " 1 " (Witczak et al. 2002).

$\log \left|\mathrm{E}^{*}\right|=\delta+\frac{\alpha}{1+\mathrm{e}^{\beta+\gamma\left(\log \mathrm{f}_{\mathrm{r}}\right)}}$

where, $f_{r}=$ reduced frequency at reference temperature, $\delta=$ limiting minimum modulus value, $\delta+\alpha=$ limiting maximum modulus value, $\beta, \gamma=$ fitting parameters. The parameter $\gamma$ influences the steepness of the function (i.e., rate of change between minimum and maximum), and $\beta$ the horizontal position of the turning point. In addition, $\delta$ and $\alpha$ depend on aggregate gradation, binder content, and air void content. Parameters $\beta$ and $\gamma$, on the other hand, depend on the characteristics of the asphalt binder and the magnitude of $\delta$ and $\alpha$ (NCHRP 2004).

The shift factor, $a(T)$, is used to shift the data collected at different temperatures with respect to the time of loading or frequency and to form a single smooth master curve. The shift factor is defined as

$$
\alpha(T)=\frac{f}{f_{r}}
$$

The shift factor can be calculated using the Arrhenius equation (Pellinen et al. 2003)

$\log [a(T)]=\frac{\Delta E A}{19.14714}\left(\frac{1}{T}-\frac{1}{T_{r}}\right)$

where, $T_{r}$ is the reference temperature, $T=$ the test temperature and $\triangle E A$ is activation energy (treated as a fitting parameter).

In this study, the Microsoft Excel spreadsheet with solver function was used to fit the measured data to a master curve using the Arrhenius temperature shift factors in equation " 3 ". The solver function tool targeted to minimize the sum of the squared error between the predicted and measured values.

\section{vi. Discussion of Test Results}

For each test section (either base or wearing course), three identical specimens were cored and tested for dynamic modulus. The average of the three test results was used to interpret the data. Master curves were constructed using the measured dynamic modulus at different temperatures and frequencies.

Researchers selected two sections i.e., Section 2 and 4 to assess the changes of the asphalt mixture's mechanical performance in the field due to aging. In the laboratory, specimens were prepared by mixing virgin materials and binders according to the mixture design of pavement test sections (Section 2 and 4) at the same temperature used in the plant. Dynamic modulus tests were performed on the unaged 
and field aged specimens for both layers. Table 2 and Table 3 show the summary of average dynamic modulus test results on unaged and field aged specimens for wearing and base mixtures, respectively. As one could expect, the dynamic modulus increased due to aging in the field for both wearing and base mixtures. For example, the dynamic modulus for Section 4 wearing mixture at $0.1 \mathrm{~Hz}$ frequency increased from 12732 to $18316 \mathrm{MPa}, 3648$ to $8654 \mathrm{MPa}$ and 319 to $2274 \mathrm{MPa}$ for test at $4^{\circ} \mathrm{C}, 20^{\circ} \mathrm{C}$ and $40^{\circ} \mathrm{C}$, respectively due to aging in the field. Similarly, for Section 4 base mixtures, the dynamic modulus at $0.1 \mathrm{~Hz}$ frequency increased from 12052 to 14369 $\mathrm{MPa}, 2760$ to $6658 \mathrm{MPa}$ and 222 to $1296 \mathrm{MPa}$ for test at $4^{\circ} \mathrm{C}$, $20^{\circ} \mathrm{C}$ and $40^{\circ} \mathrm{C}$, respectively. The increase of dynamic modulus due to aging in the field is higher for wearing mixture compared to base mixture because the asphalt mixture at greater depth (base layer) gets lesser contact with air and hence less oxidized. Furthermore, the effect of densification is most prominent at the upper wearing course and gradually decreases with depth towards bottom of base layer.

Fig. 6 and Fig. 7 show the master curve comparison for unaged and field aged specimens for both layers. It can be observed that for unaged mixtures, dynamic modulus master curves for both base and wearing mixture is lying very close to each other. However, for field aged mixtures, master curve for wearing layer is well above the base layer at high temperaturelow frequency region of master curve.

\section{TABLE 2. DYNAMIC MODLUS COMPARISON FOR UNAGED} AND FIELD AGED WEARING MIXTURE

\begin{tabular}{|c|c|c|c|c|c|c|c|c|c|}
\hline \multirow{2}{*}{$\begin{array}{c}\text { Loading } \\
\text { Condition }\end{array}$} & \multicolumn{4}{|c|}{ Section-2 } & \multicolumn{4}{c|}{ Section-4 } \\
\cline { 2 - 10 } $\begin{array}{c}\text { Temp. } \\
{ }^{\circ} \mathrm{C}\end{array}$ & $\begin{array}{c}\text { Ereq. } \\
\mathrm{Hz}\end{array}$ & $\left|\boldsymbol{E}^{*}\right|$ & $\begin{array}{c}\text { Phase } \\
\text { angle }\end{array}$ & $\left|\boldsymbol{E}^{*}\right|$ & $\begin{array}{c}\text { Phase } \\
\text { angle }\end{array}$ & $\left|\boldsymbol{E}^{*}\right|$ & $\begin{array}{c}\text { Phase } \\
\text { angle }\end{array}$ & $\left|\boldsymbol{E}^{*}\right|$ & $\begin{array}{c}\text { Phase } \\
\text { angle }\end{array}$ \\
\hline \multirow{4}{*}{4} & 0.1 & 13964 & 17.9 & 18760 & 9.0 & 12732 & 18.4 & 18316 & 8.5 \\
\cline { 2 - 10 } & 1 & 20076 & 12.5 & 22540 & 6.9 & 18465 & 13.1 & 21751 & 6.7 \\
\hline & 10 & 26256 & 8.9 & 26216 & 5.6 & 24359 & 9.2 & 24742 & 5.5 \\
\hline \multirow{4}{*}{20} & 0.1 & 3522 & 32.1 & 8362 & 19.4 & 3648 & 32.3 & 8654 & 17.7 \\
\cline { 2 - 10 } & 1 & 7247 & 26.6 & 12174 & 15.1 & 7275 & 26.4 & 12134 & 13.6 \\
\cline { 2 - 10 } & 10 & 12351 & 19.9 & 16518 & 11.4 & 12293 & 19.6 & 16057 & 10.4 \\
\hline \multirow{4}{4}{40} & 0.01 & 134 & 24.5 & 850 & 31.4 & 139 & 23.0 & 1033 & 33.8 \\
\cline { 2 - 9 } & 0.1 & 320 & 30.6 & 1900 & 32.9 & 319 & 30.8 & 2274 & 31.8 \\
\cline { 2 - 9 } & 1 & 982 & 35.1 & 3850 & 28.6 & 938 & 35.5 & 4276 & 26.9 \\
\cline { 2 - 9 } & 10 & 2961 & 35.0 & 7030 & 23.1 & 2757 & 35.4 & 7300 & 21.3 \\
\hline
\end{tabular}

\# Values of $\left|E^{*}\right|$ are in MPa and phase angle in degree

TABLE 3. DYNAMIC MODLUS COMPARISON FOR UNAGED AND FIELD AGED BASE MIXTURE

\begin{tabular}{|c|c|c|c|c|c|c|c|c|c|}
\hline \multicolumn{2}{|c|}{$\begin{array}{c}\text { Loading } \\
\text { Condition }\end{array}$} & \multicolumn{4}{|c|}{ Section-2 } & \multicolumn{4}{c|}{ Section-4 } \\
\cline { 2 - 11 } $\begin{array}{c}\text { Temp. } \\
{ }^{\circ} \mathrm{C}\end{array}$ & $\begin{array}{c}\text { Freq. } \\
\mathrm{Hz}\end{array}$ & $\left|E^{*}\right|$ & $\begin{array}{c}\text { Phase } \\
\text { angle }\end{array}$ & $\left|E^{*}\right|$ & $\begin{array}{c}\text { Phase } \\
\text { angle }\end{array}$ & $\left|E^{*}\right|$ & $\begin{array}{c}\text { Phase } \\
\text { angle }\end{array}$ & $\left|E^{*}\right|$ & $\begin{array}{c}\text { Phase } \\
\text { angle }\end{array}$ \\
\hline \multirow{4}{*}{4} & 0.1 & 12305 & 15.9 & 14357 & 15.6 & 12052 & 20.1 & 14369 & 10.7 \\
\cline { 2 - 11 } & 1 & 16786 & 11.4 & 19813 & 8.9 & 17952 & 13.9 & 21060 & 8.0 \\
\cline { 2 - 10 } & 10 & 21189 & 7.9 & 23811 & 6.7 & 23999 & 9.5 & 25035 & 6.4 \\
\hline \multirow{4}{*}{20} & 0.1 & 4115 & 28.7 & 5447 & 24.1 & 2760 & 35.3 & 6658 & 22.2 \\
\cline { 2 - 10 } & 1 & 7354 & 23.5 & 8929 & 19.3 & 6105 & 29.6 & 10023 & 17.8 \\
\cline { 2 - 10 } & 10 & 11520 & 17.4 & 13105 & 14.4 & 10954 & 22.0 & 14006 & 13.8 \\
\hline \multirow{4}{*}{40} & 0.01 & 155 & 24.9 & 504 & 25.5 & 122 & 20.2 & 616 & 24.6 \\
\cline { 2 - 10 } & 0.1 & 581 & 29.5 & 1045 & 28.0 & 222 & 28.2 & 1296 & 27.9 \\
\cline { 2 - 9 } & 1 & 1314 & 32.7 & 2242 & 29.3 & 617 & 34.8 & 2773 & 28.6 \\
\cline { 2 - 9 } & 10 & 3240 & 33.7 & 4615 & 26.9 & 2023 & 37.5 & 5374 & 25.5 \\
\hline
\end{tabular}

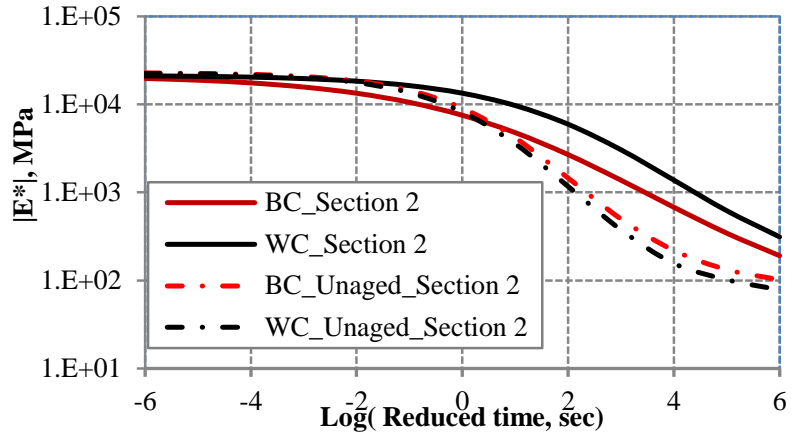

Figure 6. Comparison of master curves for unaged and aged field mixture for wearing and base layer for Section 2 (log-scale)

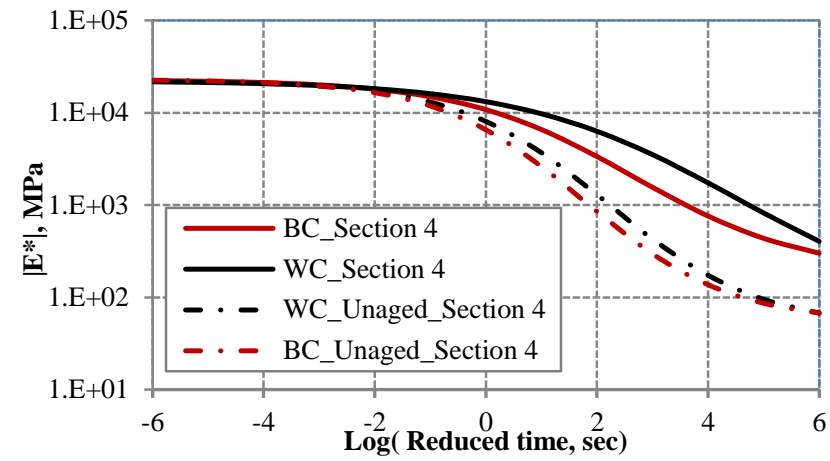

Figure 7. Comparison of master curves for unaged and aged field mixture for wearing and base layer for Section 4 (log-scale)

The effect of different bitumen types on the dynamic modulus of specimens extracted from wearing course was also studied. Fig. 8 shows the comparison between the master curves for specimens with various bitumen types. For low temperature-high frequency region, field mixture master curve is lying very close to each other as shown in Fig. 8. However, for high temperature-low frequency region, specimen with PMB (Section 5 and 6) showed highest dynamic modulus value followed by Pen 40-50 (Section 1) and Pen 60-70 specimens (Section 2, 3 and 4). This indicates PMB at high temperature becomes stiffer thus greater resistance to permanent deformation under cyclic loading in comparison to unmodified binder. The similar finding was also observed by Sadek et al. (2015) for field base layer cores.

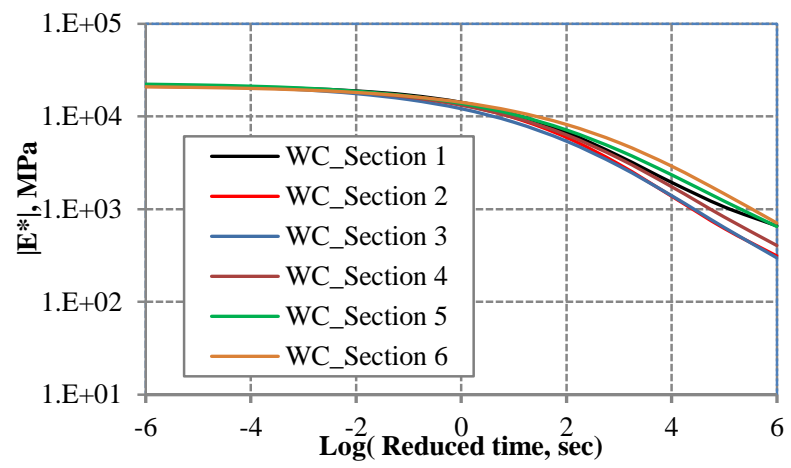

Figure 8. Comparison of master curves for field wearing cores for all sections (log-scale) 


\section{vII. Summary}

The rheological properties of asphalt binders/mixtures change due to aging. It is well documented that the level of aging was the highest at the wearing course and gradually decreased with the depth. However, most of previous studies evaluated asphalt aging with depth was conducted solely on the binders. This study demonstrated the evaluation of mechanical properties of asphalt mixture of wearing and base layer of in-service pavements in Qatar. In this study, the dynamic modulus test was performed by using an AMPT system. A total number of 18 cores were extracted from 6 pavement sections (3 cores from each test section). Test specimens were prepared from both layers and performance testing was conducted using the AMPT. The researchers tested small specimens $(50-\mathrm{mm}$ in diameter and $110-\mathrm{mm})$ cored horizontally from field wearing course, while typical specimens $(100-\mathrm{mm}$ diameter and a $150-\mathrm{mm})$ were cored and trimmed from the base layer. The dynamic modulus test results indicated that the extent of aging for wearing course is higher compared to the base layer. The wearing course is subjected to harsh weather condition of elevated temperatures compared to other underlying layers, hence, more aged. The dynamic modulus master curves of base and wearing mixtures illustrated that the effect of aging is most significant at high temperature-low frequency test condition. Furthermore, asphalt mixtures prepared with modified binders showed higher dynamic modulus at higher temperature-low frequency region in comparison to unmodified binders.

\section{Acknowledgment}

This paper was made possible by the NPRP grants (NPRP 6-773-2-320 and NPRP 7-110-2-056) from the Qatar National Research Fund (a member of Qatar Foundation). The statements made herein are solely the responsibility of the authors.

\section{References}

[1] AASHTO TP-62, Standard method of test for determining dynamic modulus of hot mix asphalt (HMA), AASHTO TP-62. American Association of State Highway and Transportation Officials, Washington, D.C., 2007

[2] A. Shenoy, and P. Romero, "Standardized procedure for analysis of dynamic modulus $\left(E^{*}\right)$ data to predict asphalt pavement distresses." J. of the Transp. Res. Board, Washington, D.C., No. 1789, pp. 173-182, 2002.

[3] B. Diefender, B. Bowers, and S. Diefenderfer, Asphalt mixture performance characterization using small-scale cylindrical specimens. VCTIR-15-R26, Virginia Department of Transportation, Richmond, Virginia, 23219, 2015.

[4] H. Sadek, E. Masad, O. Sirin, H. Al-Khalid, and K. Hassan, "Performance evaluation of full-scale sections of asphalt pavements in the state of Qatar". J. of Per. of Constructed Facilities, vol. 29 (5), 2015.

[5] NCHRP, Final Report-Guide for Mechanistic-Empirical Design of New and Rehabilitated Pavement Design Structures - Part 2 Design Inputs Chapter 2: Material Characterization, NCHRP Project 1-37A, ERES Division of ARA Inc., Champaign Illinois, USA, 2004.

[6] T. Pellinen, M. Witczak, and R. Bonaquist, "Asphalt mix master curve construction using sigmoidal fitting function with non-linear least squares optimization." Recent Advances in Materials Characterization and Modeling of Pavement Systems. pp. 83-101. doi: 10.1061/40709(257)6, 2003.

[7] TRL., Professional Consultancy Services for Road Pavement Technology, Phase D: Design of Site Trials, Client Project Report 282, PWA/CE/210/2008, 2010.

[8] TRL., A guide to the Design of Hot Mix Asphalt in Tropical and SubTropical Countries, Overseas Road Note 19, TRL Limited, 2002.

[9] P. Yan-Zhu, and W. Duan-yi, "Experimental Study on Dynamic Modulus Master Curve of ATPB Mixture," Applied Mechanics and Materials, Volumes 117-119, pp 1556-1560, 2012.

[10] O. Sirin, D. Paul, E. Kassem, M. Ohiduzzaman, "Effect of Aging on Asphalt Binders in the State of Qatar: A Case Study." J. of the Assoc. of Asphalt Paving Technologists, AAPT (in press).

[11] S. Goh, Z. You, R. Williams, and X. Li, "Preliminary dynamic modulus criteria of HMA for field rutting of asphalt pavements: Michigan's experience" J. of Transp. Eng., vol.137(1), pp.37-45, 2011.

[12] T. Pellinen, and M. Witczak, "Use of Stiffness of Hot-Mix Asphalt as a Simple Performance Test" J. of the Transp. Res. Board, Washington, D.C., No. 1789, pp. 80-90, 2002.

[13] M.Witczak, K. Kaloush, T. Pellinen, M. El-Basyouny, and H. Von Quintus, Simple Performance Test for Superpave Mix Design, NCHRP Report 465. Transportation Research Board-National Research Council, Washington, D.C., USA, 2002.

About Author (s):

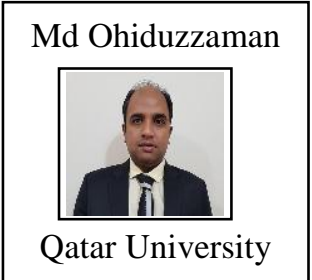

[Dynamic modulus is one of the important performance criteria to characterize the mechanical properties of asphalt mixtures.]

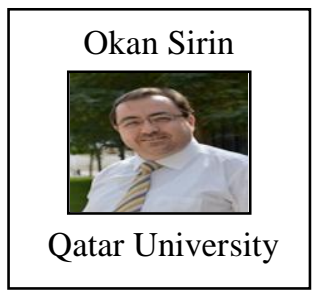

[The wearing course is subjected to harsh weather condition of elevated temperatures compared to other underlying layers.]

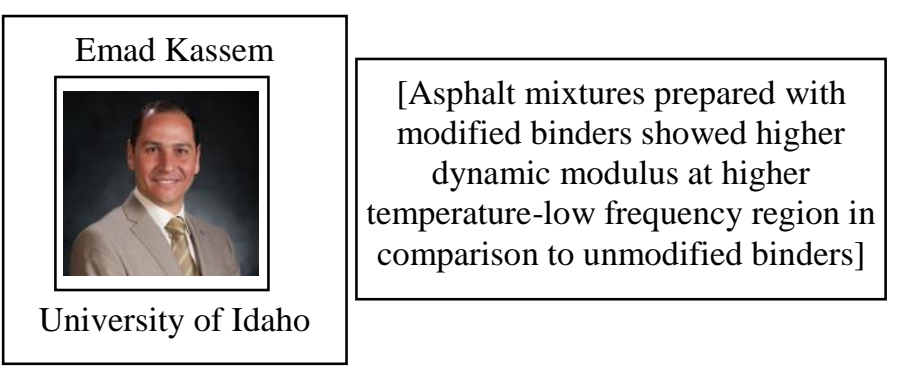

